\title{
CANDIDÍASE EM PACIENTES AIDÉTICOS
}

\author{
C.E.O.P. Campos, R.P. Igreja e E.P. Campos
}

\begin{abstract}
Trinta e cinco aidéticos entre 19 e 55 anos admitidos e tratados de candidiase no Hospital Emilio Ribas, SP, com ELISA positivo para HIV e confirmado pelo Western Blot. Tuberculose em 9 sendo 2 com pericardite; neurotoxoplasmose em 6; neurocriptococose em 5; herpes labial em 4; pneumocistose em 3 e sarcoma de Kaposi em 2, achavam-se associadas. A concentração inibitória mínima 50\% (MIC 50\%) para os azoles foi: ketoconazol = 2,2 $\mu \mathrm{g} / \mathrm{ml}$; itraconazol= $21,0 \mu \mathrm{g} / \mathrm{ml} ;$ fluconazol $=19,0 \mu \mathrm{g} / \mathrm{ml}$. O MIC 50\% para os polienos: nistatina $=50,0 \mu \mathrm{g} / \mathrm{ml}$; anfotericina $B=0,12 \mu \mathrm{g} / \mathrm{ml}$ e para 5 fluorcitosina $=1,6 \mu \mathrm{g} / \mathrm{ml}$ nas 35 amostras de Candida isoladas. Testes não paramétricos de Siegel revelaram significante identificação (80\%) das Candida albicans na candidíase, e que a dose de $A M B$ não modificou o número de óbitos, precoce e tardio, ocorridos nesses aidéticos. O uso prévio dos azoles e da nistatina explicaria, talvez, o elevado MIC 50\% observado nas amostras de Candida isoladas.
\end{abstract}

Palavras-chaves: Candidiase. AIDS. Terapia: polienos e imidazóis.

Candidíase é a doença fúngica mais comum e, geralmente, ocorre como infecção oportunista em doentes debilitados. Atinge as membranas e a pele humana, porém, a sua simples presença no organismo não significa doença.

$\mathrm{O}$ agente mais freqüente de candidíase é a Candida albicans seguida por C. tropicalis, $C$. guillermondi, C. parapsilosis, entre outras $^{891012131415}$. Fatores enzimáticos, proteinase e a fosfatase, liberados pelo fungo facilitam a sua disseminação em indíviduos imunodeprimidos e/ ou imunossuprimidos 7911131415 .

A deficiência de vitaminas A e D propiciaria o aparecimento de candidíase mucocutânea e, eventualmente, sistêmica em indivíduos josos. A candidemia ocorre em condições iatrogênicas e/

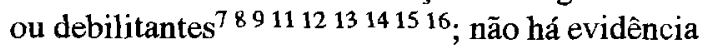
clínica de infecção e o quadro evolutivo é insidioso e inespecífico a exemplo, da candidíase invasiva nos portadores de síndrome de imunodeficiência humana (AIDS).

As portas de entrada, a saber: orofaringe, cateter intravenoso e a contaminação de sangue humano em seringas favorecem a invasão do agente fúngico no organismo. A endocardite pode surgir, principalmente, após cirurgia de

\footnotetext{
Depto. de Microbiologia e Imunologia - Instituto de Biociências, Universidade Estadual Paulista, Botucatu, SP e Hospital Emilio Ribas, São Paulo, Brasil.

Endereģo para correspondência: Dra. Claudia E.O.P. Campos, Depto. de Microbiologia e Imunologia. Instituto de Biociências da UNESP. 18618-000 Botucatu, SP.

Recebido para publicação em 26/02/92.
}

prótese valvular cardíaca e pelo uso abusivo de drogas $^{71121315}$.

A forma digestiva (oral, esofágica, estômago e intestinal) é grave e desenvolve-se, freqüentemente, em aidéticos. Nas doenças neoplásicas consumptivas e nos imunodeprimidos (aidéticos) surgem a forma pneumônica da candidíase 789121516 .

Resolveu-se estudar em pacientes com diagnóstico presuntivo de AIDS e candidíase oral, internados no Hospital Emúlio Ribas, São Paulo, as seguintes proposiçôes:

1. Isolamento e identificação de candidíase oral;

2. Determinação da Concentração Inibitória Mínima (MIC) $50 \%$ das amostras de Candida frente aos azoles (ketoconazol, itraconazole fluconazol); polienos (anfotericina B - AMB e nistatina NIS) e a base citosina - 5 fluorcitosina $(5 \mathrm{FC})$.

3. Os resultados clínico-laboratoriais evolutivos obtidos no primeiro ano de seguimento desses doentes.

\section{MATERIAL E MÉTODOS}

Foram selecionados 35 doentes recém internados no Hospital Emílio Ribas, São Paulo, com candidíase oro-esofágica e diagnóstico presuntivo de AIDS, no período de março a novembro de 1989.

Elaborou-se, para o presente estudo, ficha clínica com dados pessoais e clínico laboratorial epidemiológico e das patologias associadas nesses pacientes. 
Campos CEOP, Igreja RP, Campos EP. Candidiase em pacientes aidéticos. Revista da Sociedade Brasileira de Medicina Tropical 25:165-169, jul-set, 1992.

\section{Avaliação laboratorial}

Os resultados laboratoriais obtidos na evolução clínica dos 35 doentes foram fundamentais para a confirmação diagnóstica de: AIDS em 30 dos 35 doentes com a pesquisa de anticorpos antivírus de imunodeficiência humana (ELISA e Western Blot). Para as doenças associadas e/ou oportunistas, foram usados métodos de boa sensibilidade e especificidade.

No diagnóstico laboratorial da candidíase, foi utilizado na colheita de material das lesões suspeitas, uma zaragatoa estéril, umedecida em caldo Sabouraud e enviada imediatamente ao Laboratório Clínico do Hospital Emílio Ribas, seção de Microbiologia. Após a semeadura em agar Sabouraud dextrose e colocado em estufa a $37^{\circ} \mathrm{C}$ por 24 a $72 \mathrm{~h}$ eram examinados diariamente a fim de se verificar o crescimento de colônias. A seguir, realizava-se um esfregaço e corava-se pelo método de Gram com o objetivo de se observar a existência de células leveduriformes com brotamentos ou não. Na presença de leveduras, cultivavam-se as mesmas em agar Sabouraud dextrose e, concomitantemente, realizava-se a técnica de formação de tubo germinativo segundo Reynolds \& Braude ${ }^{17}$. As amostras produtoras de tubo germinativo, foram classificadas como Candida albicans e as demais foram denominadas de Candida spp.

Oestudo do MIC foi realizado segundo Campos ${ }^{5}$ e a partir dos dados obtidos no MIC frente aos: azoles (ketoconazol, itraconazol e fluconazol); polienos: AMB e NIS e a 5 FC determinaram-se os MIC $50 \%$ das amostras.

\section{Critério de cura}

A sobrevida ou não foi verificada 12 meses após a internação que motivou o presente estudo, considerando-se óbito precoce quando a morte ocorreu até a dose total de $300 \mathrm{mg}$ de AMB e/ou nos primeiros três meses de internação; e óbito tardio quando a morte ocorreu na dose superior a $500 \mathrm{mg}$ de $A M B$ e/ou após 5 meses da internação.

\section{Análise estatística}

Utilizaram-se os testes paramétricos do $\mathrm{x}^{2}$ para análise da distribuição de Candida albicans e da evolução terapêutica nos aidéticos ${ }^{18}$. Todos os testes estatísticos foram efetuados ao nível de $5 \%$ de significância.

\section{RESULTADOS}

Os 30 pacientes com AIDS recém-internados no Hospital Emílio Ribas, SP, com candidíase oral, apresentavam idade entre 19 a 55 anos, com maior freqüência na faixa etária de 20 a 40 anos, e predomínio da raça branca sobre a raça negra e do sexo masculino sobre o feminino, respectivamente, na proporção de $4: 1$ e de $3: 1$.

A tuberculose em 9 e as demais doenças oportunistas relatadas, inclusive o sarcoma de Kaposi, foram observadas nesses pacientes com AIDS.

A utilização de drogas antifúngicas e imunossupressoras foi designada: terapêutica em 26; profilática em 5 e imunossupressora em dois, sendo a NIS (14), o ketoconazol (9) e a terapia tríplice (6) as mais empregadas.

Os 30 doentes com candidíase revelaram nas amostras isoladas eidentificadas a Candida albicans em $28(80 \%)$ deles.

As MIC 50\% realizadas nos azoles, polienos e 5 FC contra amostras de Candida acham-se expressas na Tabela 1. As MIC 50\% foram elevadas para os azoles (itraconazol $21 \mu \mathrm{g} / \mathrm{ml}$, fluconazol 19 $\mu \mathrm{g} / \mathrm{ml}$ ) e $50 \mu \mathrm{g} / \mathrm{ml}$ para a NIS.

Tabela 1 - Concentração inibitória minima (MIC) 50\% de 35 amostras de Candida spp isoladas de aidéticos frente aos azoles, polienos e 5 fluorcitosina.

\begin{tabular}{llr}
\hline & Antifúngicos & $\begin{array}{c}\text { MIC 50\% } \\
(\mu / \mathrm{ml})\end{array}$ \\
\hline Azoles & ketoconazol & 2,20 \\
& $\begin{array}{l}\text { itraconazol } \\
\text { fluconazol }\end{array}$ & 21,00 \\
& & 19,00 \\
Polienos & anfotericina B & 0,12 \\
& nistatina & 50,00 \\
& & \\
Base citosina & 5 fluorcitosina & 1,60 \\
\hline
\end{tabular}

\section{Cura}

Após um ano de internação observou-se em 30 doentes: óbito precoce: < $300 \mathrm{mg}$ de AMB - 12; óbito tardio: > $300 \mathrm{mg}$ de AMB - 6 . 
Campos CEOP, Igreja RP, Campos EP. Candidiase em pacientes aidéticos. Revista da Sociedade Brasileira de Medicina Tropical 25:165-169, jul-set, 1992.

\section{Análise estatística - Teste de Siege ${ }^{18}$}

As amostras de Candida albicans foramisoladas em maior proporção nas Candida dos 35 aidéticos.

$A$ dose de $A M B$ não modificou, de modo significativo, o número de óbitos, precoce e tardio, ocorridos nos 35 pacientes.

Tabela 2 - Proporçâo de Candida albicans isoladas de trinta aidéticos.

Candida albicans

Candida spp

Total

28

7

35

$\mathrm{x}^{2}=12,60(\mathrm{p}<0,001) \mathrm{s}$.

Tabela 3 - Sobrevida e óbitos ocorridos na evolução terapêutica de trinta aidéticos.

\begin{tabular}{cccc}
\hline \multirow{2}{*}{ Sobrevida } & \multicolumn{2}{c}{ Óbitos } & Total \\
\cline { 2 - 3 } & $\mathrm{AMB}<300 \mathrm{mg}$ & $\mathrm{AMB}>500 \mathrm{mg}$ & \\
\hline 12 & 12 & 6 & 30
\end{tabular}

$x^{2}=2,40(p>0,05)$ n.s.

\section{DISCUSSÃo}

A candidíase foi sem dúvida, a grande expressão da AIDS nos 30 doentes avaliados de acordo com relatos da literatura ${ }^{912} 1315$. A forma mucosa oral traduz imunossupressão iatrogênica e foi assinalada em $59 \%$ dos homossexuais ${ }^{12} 15$. Além disso, é a forma mais frequente da candidíase em aidéticos, enquanto formas ungueais e peromqueas são mais assinaladas em outras condições predisponentes presentes nesses indivíduos $^{9121315}$.

O paciente aidético é um meio adequado à disseminação da candidíase pela imunodepressão ou pelos fatores enzimáticos que diminuem na parede do tubo digestivo 71114 16. A proliferação fúngica, portanto, transformaria o estágio de portador no de sintomático e seria indicadora de candidíase digestiva e de outros sítios $\left(\right.$ Odds $^{13}$, Odds e coll $^{14}$ e Pike e col $^{16}$ ).

Odds $^{13}$ e Odds e col ${ }^{14}$ propuseram, ainda, que a recuperação de menos de 10 unidades formadoras de colônias em cultura de um "swab" vaginal seria indicativo de portador assintomático. Logo, a presença de células de Candida deve suprimir a resposta imune local e facilitar a reinfecção, principalmente em aidéticos e/ou fatores predisponentes presentes nesses indivíduos Pike e $\mathrm{col}^{16}$.

O uso prévio da NIS nas Candida isoladas da lesão oral dos aidéticos, explicaria os MIC 50\% obtidos no presente estudo, análogo ao descrito por alguns investigadores ${ }^{1236810}$.

A AMB revelou sua eficácia ao manter níveis baixos de MIC $50 \%$ nas amostras ensaiadas. A resistência da candidíase à $A M B$ parece ser eventual e, além disso, não foi observada na presente casuística $^{246810}$. A verificação pelos testes não paramétricos de Siegel ${ }^{18}$ na distribuição de Candida albicans na candidíase foi significativa, no entanto, houve um incremento das outras espécies de Candida nos aidéticos. Este fato deve ser observado com atenção pelas características imunossupressivas e iatrogênicas dos aidéticos ${ }^{1314}$. A fase IV da infecção pelo HIV seria uma condição predisponente ao desenvolvimento da candidíase. A presença de outras espécies seria justificada pela defesa imunológica diminuída e pela redução de oxigênio aos tecidos que permitiriam maior proliferação de Candida ssp nesses doentes ${ }^{11} 131416$, além das pressões seletivas das drogas utilizadas na fase aidética contribuírem para o comportamento acima assinalado 13461014 .

Os polienos e os azoles agem sobre a membrana modificando sua permeabilidade pela interferência nos componentes lipídicos dos fungos ${ }^{2} 4610$, enquanto que a resitência da Candida à NIS foi constatada por Bodenhoff ${ }^{3}$ e Athar \& Winner ${ }^{2}$.

Campos $^{5}$ observou: resistência cruzada entre NIS e AMB; que a linhagem sem resistência mostrou crescimento mais exuberante, na ausência de antibióticos, em relacão às mutantes resistentes e, após eliminar a resistência à NIS pela ação da acriflavina, o crescimento da Candida albicans não se alterou. Concluiu, portanto, que a resistência à NIS, nesse caso era do tipo cromossomal.

Observou-se, ainda, que a elevada resistência das Candida da para os azoles permitiu sugerir que mecanismos distintos e sítios de ação diferentes conduziram às ações semelhantes sobre o esterol da membrana e à resistência fúngica assinalada $^{15} 6810$. Por outro lado, a resistência 
Campos CEOP, Igreja RP, Campos EP. Candidiase em pacientes aidéticos. Revista da Sociedade Brasileira de Medicina Tropical 25:165-169, jul-set, 1992.

cruzada entre NIS e os azoles, assim como entre os polienos NIS e AMB foram relatadas 123456810 . Além disso, foi observado a infecção cruzada por Candida albicans em doentes das unidades hospitalares de terapia intensiva ${ }^{8} 12$.

Portanto, as internaçôes anteriores aliadas ao uso profilático dos azoles e dos polienos, principalmente a NIS, constituiriam as razões básicas para a explicação da elevada resistência fúngica observada em nossa casuística.

\section{SUMMARY}

A total of 35 in patients admitted at Emilio Ribas Hospital - São Paulo, Brazil, with digestive candidiasis and AIDS clinical diagnostic were evaluated 10 month later, being 29 male and 6 female; white outnumbering black with age ranged from 30 to 50 years old. Agar
Sabouraud culture and tube germinative tests identified 28 (80\%) Candida albicans out 35 strains. Minimum inhibitory concentration (MIC) $50 \%$ was against azoles (ketoconazole $=2.2 \mu \mathrm{g} / \mathrm{ml} ;$ itraconazole $=21.0 \mu \mathrm{g} / \mathrm{ml}$ and fluconazole $=19.0 \mu \mathrm{g} / \mathrm{ml}$ ); polyenes (nystatine $=$ $50.0 \mu \mathrm{g} / \mathrm{ml}$ and amphotericin $B=0.12 \mu \mathrm{g} / \mathrm{ml}$ ) and 5 fluorcytosine $=1.6 \mu \mathrm{g} / \mathrm{ml}$. Siegel tests showed significant Candida albicans proportions in strains isolated from 35 AIDS patients. There was no significant relation between $A M B$ dosis and early or late death. Conclusions: candidiasis in AIDS patients showed high MIC 50\% to azoles and nystatine and significant Candida abicans proportion in all strains isolated from AIDS patients. Previous amphotericin B therapy had no influence in early or late death in 30 patients. Previous therapy possibily explained MIC 50\% increases in Candida strains.

Key-words: Candidiasis. AIDS. Therapy: polyenes and imidazoles.

\section{REFERÊNCIAS BIBLIOGRÁFICAS}

1. AckerbauerH, Meingassner JG, Mieth H. Preclinical antimycotic activity of SDZ 89-485: a new orally and topicaly effective triazole. Journal Medical Veterinary Mycology 29:445-454, 1990.

2. Athar MA, Winner HI. The development of resistance by Candida species to polyene antibiotics in vitro. Journal of Medical Microbiology 4:505-517, 1971.

3. Bodenhoff $\mathbf{J}$. Development of strains of genus Candida and genus Torulopsis resistant to antimycotics. Acta Pathologica Microbiologica Scandinava 75:622-630, 1969.

4. Bratyburg J, Powderly WG, Kobayashi GS, Medoff $X$. Amphotericin B: current understanding of mechanism of action. Antimicrobial Agents Chemotherapy 34:183-188, 1990.

5. Campos CEOP. Resistência de Candida albicans a nistatina e anfotericina B. Alterações no crescimento de mutantes resistentes. Tese de doutorado. Universidade de São Paulo, Botucatu, SP, 1974.

6. Christine BM, Bard M, Lees ND. Polyene resistance in ergosterol producing strains of Candida albicans. Mycoses 34:75-83, 1991.

7. Cole GF, Lynn KT, Seshon KR, Pope LM. Gastrointestinal and systemic candidosis in immunocompromised mice. Journal Medical Veterinary Mycology 27:363-380, 1989.

8. Conly J, Rennie R, Johnson J, Farah S. Disseminated candidiasis due to amphotericin B - resistant Candida albicans. Journal of Infectious Diseases
165:761-764, 1992.

9. Edwards $\mathrm{J}_{\Gamma} \mathrm{JE}$. Candida species. In: Mandell GL, Gordon Douglas JrR, Bennett JE (ed) Principles and practive of infectious diseases. John Wileys Sons, New York p. 1435-1447, 1985.

10. Hitchcock CA, Barrett-Bee KS, Russell NJ. The lipid composition and permeability to azole of an azole and polyene-resistant mutant of Candida albicans. Journal Medical Veterinary Mycology 25:29-37, 1987.

11. Hunter PR, Harrison GAJ, Traser CAM. Cross infection and diversity of Candida albicans strain carriage in patients and nursing staff on an intensive care. Journal Medical Veterinary Mycology 28:317326, 1990.

12. McKenzie R, Travis WD, Dolan SA, Pittaluga $S$, Fenerstein IM, Shelhamer J, Yarchoan R, Mansur $H$. The causes of death in patients with human immunodeficiency virus infection. A clinical and pathology study with emphasis on the role of pulmonary diseases. Medicine 70:326-343, 1991.

13. Odds FC. Candida and Candidosis. $2^{\text {nd }}$ edition. London-Philadelphia-New York - Tokio - Balliere Tindall, 1988.

14. Odds FC, Webster CE, Mayranathan P, Simmons PD. Candida concentrations in the vagine and their association with signs and symptons of vaginal candidosis. Journal Medical Veterinary Mycology 26:277-284, 1988. 
Campos CEOP, Igreja RP, Campos EP. Candidíase em pacientes aidéticos. Revista da Sociedade Brasileira de Medicina Tropical 25:165-169, jul-set, 1992.

15. Penneys NS. Skin manifestations of AIDS. $1^{\text {st }}$ edition. Martin Dunitz LTD, London, 1990.

16. Pike WJ, Clarke J, Lacey CJN, Hunter PA, Evans EG. Candida cell wall mannan in the vagina and its association with the signs and symptoms of vaginal candidosis. Journal Medical Veterinary Mycology 29:305-312, 1991.
17. Reynolds $R$, Braude AI. The filament inducing property of blood for Candida albicans; its nature and significance. Clinical Research Proceeding 4:4044, 1956.

18. Siegel S. Estatística não paramétrica. Editora McGraw Hill, 1975. 